\title{
The Transfer Mechanism of Pollution Industry in China Under Multi-factor Combination Model-Based on Industry, Location and Environment Perspectives
}

chuang li ( $\sim$ lichuang@hpu.edu.cn )

Henan Polytechnic University https://orcid.org/0000-0002-5934-6343

wenjing xia

Henan Polytechnic University

liping wang

Jimei University

\section{Research Article}

Keywords: pollution industry transfer, triangle model, multi factor combination, ecological environment

Posted Date: February 16th, 2021

DOI: https://doi.org/10.21203/rs.3.rs-192408/v1

License: (c) (i) This work is licensed under a Creative Commons Attribution 4.0 International License.

Read Full License 


\section{The transfer mechanism of pollution industry in China under multi-factor combination model}

\section{- - Based on industry, location and environment perspectives}

Chuang $\mathrm{Li}^{1}$, Wenjing Xia ${ }^{1}$, Liping Wang ${ }^{{ }^{*}}$

1. Research Center for Energy Economics, Henan Polytechnic University, Jiaozuo 454000, China

2. Finance and Economics College, Jimei University, Xiamen 361021, China

* Correspondence: lindsey18@jmu.edu.cn (L.W.)

Abstract: In the process of industry transfer, how to ensure the sustainable development of ecological environment is a very important problem for every local government. Therefore, this paper introduces environmental factors into the transfer mechanism of pollution industry, establishes a Triangle Model, and empirically studies the transfer mechanism of China's pollution industry under various combination scenarios based on the panel data of 30 provinces in 2000-2015. The results show that: (1) The pollution industry transfer is the result of the change of regional competitive advantages; the industrial advantage is the primary factor of pollution industry transfer in China and is positive role in attracting industrial transfer. (2) With the continuous promotion of regional coordination strategy and ecological civilization construction, the attraction of regional factors to industry transfer has been reduced, and the inhibition of environmental factors to pollution industry is increasing. In addition, it is worth noting that China's pollution industry had not gone to "innovation highland" but "environmental depression" during the research period, that is, the phenomenon of $\mathrm{PHH}$ more likely happened during the process of industry transfer among Chinese provinces. The paper suggests that all provinces should adhere to the concept of green development and promote industrial transformation and upgrading through industry transfer.

Keywords: pollution industry transfer; triangle model; multi factor combination; ecological environment

\section{Introduction}

With the deepening of reform and opening, industrial development has achieved tremendous results in China, the long-term extensive economic development has also caused a series of ecological environment problems, for instance the frequent haze weather, serious water pollution, resource depletion and so on. According to the "China Eco-Environmental Status Bulletin 2018", 217 cities of 338 prefecture-level cities in China exceeded the national standard in air quality in 2018, accounting for more than two-thirds of the total; in which, 338 cities monitored had 1899 days of severe pollution and 822 days of serious pollution. It reveals that the environmental pollution problem in China is rather serious. Therefore, the construction of ecological civilization needs to be strengthened in China. Since the Eighteenth National Congress of the CPC, the CPC Central Committee has attached great importance to the construction of ecological civilization and integrated it into the overall strategic layout of "five in one". The Nineteenth National Congress of the CPC emphasized that the ecological environment should be treated as life. In this context, in order to speed up the upgrading of the local industrial structure, the economically developed regions of eastern China have proposed industrial withdrawal lists. For example, on the basis of the Guiding Catalogue of industrial transfer (2018 version) issued by the Ministry of industry and information technology, the provinces and cities have all formulated the "Industrial Structure Adjustment Plan", and clarified the leading and coordinating departments for key tasks, with the aim of accelerating the implementation of reduction adjustments and regional transformation and development in key industries. The Department of Industry and Information Technology of Guangdong Province has issued the notice of Guangdong Province on promoting the 
withdrawal of backward production capacity in 2019 (Guangdong industry and Information Technology Planning Certificate Policy letter [2019] No. 830); Shenzhen city has announced a list of specific industries for the withdrawal of backward industry in 2019, including 12 energy consumption categories, 12 environmental protection categories, 12 process equipment categories, and more than 50 industries.

At the same time, in order to speed up economic development in Central and Western China, the competition between provinces around doing well industrial undertakings and increasing investment attraction is becoming increasingly fierce. Therefore, how to avoid polluting industries taking the ride of industrial transfer, effectively combine industrial transfer with industrial transformation and upgrading, and realize the harmonization of industrial development and ecological environmental protection. It is necessary to reexamine the transfer mechanism and motivation of the pollution industry in the new era, which is of great practical significance for all parts of the country to formulate industrial development strategies and standardize investment promotion activities.

The main works of this paper are as follow:

1. Different from the existing literatures concerning economic, social and technological factors, the paper proposes would pay more attention to the ecological carrying capacity in the research of pollution industry transfer under the background of Chinese ecological civilization construction.

2. The paper establishes the triangle model including three factors of industry, location and environment and analyzes the transfer mechanism of pollution industry in China.

3. Pollution industry had not transfer to "innovation highland" but "environmental depression" from 2000 to 2015 year in China.

\section{Literature Review}

Foreign studies on industrial transfer focus on developed countries, which can be traced back to the life cycle theory, put forward by Vernon (1966), i.e., the process of industrial development experiencing emergence, development, prosperity and recession, and the cross-regional transfer of dying industry is to prevent their withdrawal from the historical stage. In addition, Dunning (1977) has drawn the international production eclectic theory for the transnational corporation's external transfer behavior, in his view, competitive advantage, location condition and internalization advantage are the three necessary and indispensable conditions for industrial transfer.

In the process of studying transnational transfers, Walter \& Ugelow (1979) observed the migration of pollution-intensive industries in developed countries (such as Western Europe, North America and Japan) to developing countries, and the export of pollution-intensive products from developing countries in international trade continued to expand, consequently, the famous "Pollution Heaven Hypothesis" (PHH) has been proposed accordingly (Walter et al. 1979). So far, the transfer of pollution industry has attracted wide attention in academia, politicians and business circles. Especially, the most controversial issue is whether there is a transfer of pollution industry, which has lasted until now.

Many scholars have confirmed the existence of the PHH (Jaffe et al. 1995; Jeppesen et al. 2002; Shen et al. 2019). At first, most scholars studied the transfer of polluting industries from the perspective of international trade and foreign investment, and believed that the transfer of polluting industries not only caused damage to the local ecological environment, resulting in the area becoming a "pollution heaven" (Levinson 1996; Wang et al. 2019; Sarkodie et al. 2019). With the continuous promotion of environmental protection policies, the developed regions continue to strengthen environmental regulation to force the transfer of polluting industries. For example, when Mulatu et al. (2010) studied the polluting industries in Europe, they found that the government's strengthening of environmental regulation would increase the "compliance cost" of the industries, resulting in the polluting industries more inclined to countries with loose environmental regulation. 
However, some studies show that after the transfer of pollution intensive industries to developing countries, the $\mathrm{PHH}$ is possible in the short term, but the $\mathrm{PHH}$ is impossible in the long-term (Kubicova 2014; Millimet et al. 2016). Zhang et al. (2017) studied the relationship between the Western Development Strategy in China and the PHH and found that the former did not lead to the western region became pollution haven. There is still a great controversy on whether the PHH is tenable. Dou \& Han (2019) studied the transfer of polluting industries in China from the perspective of industrial mobility, and proved that the transfer of polluting industries under environmental regulations is comprehensive effect of "pollution havens" and "innovation compensation" in China.

While testing the $\mathrm{PHH}$, scholars have also conducted in-depth research on the causes of pollution industry transfer. Because different scholars pay attention to different factors, their conclusions are also inconsistent. In summary, there are the following aspects:

Firstly, the impact of regional environmental regulation level. Due to the imbalance of economic development, the developed regions continue to restrict environmental regulation policy, result the polluting industry to transfer to the areas with relatively loose environmental policy (Levinson 1996; Xing et al. 2002; Tang 2015; D'Agostino 2015). However, Zhao \& Sun (2016), Cheng (2017), Yuan (2017), Ran \& Xu (2019) and others believe that appropriate environmental regulation can promote technological innovation of enterprises, reduce pollution emissions, promote the coordinated development of economy and environment and reduce the environmental pollution effect of the receiving region. When studying the relationship between environmental regulation and the transfer of polluting industries, it is still necessary to find out whether environmental factors are the first incentive for the transfer of polluting industries. In other words, how much role do environmental factors play in the transfer of polluting industries, so much pollution industries need to evade the adverse effects of environmental regulation through regional migration.

Secondly, location factors are the important reasons for the transfer of polluting industries. $\mathrm{Gu}$ (2013), Wu (2017), Li (2018) believe that factor cost and labor cost are the main drivers of the migration of polluting industries; Liang (2016), Guan (2018) and others believe that economic extroversion, industrial agglomeration and tax policies have important impact on the transfer of polluting industries. From the existing research, the area factor involves lot of fields, both "hard constraint" indicators reflecting the natural conditions of the region and "soft constraint" indicators reflecting the level of location management and the research results are very rich.

Thirdly, industrial transformation is another factor for the transfer of polluting industries, especially the impact of technological innovation. After the economy develops to a certain stage, with the need for economic system reform and industrial structure adjustment and upgrading, polluting industries are given priority to transfer (Zhao et al. 2015; Li et al. 2016; Zhou et al. 2015). Duan \& Wen (2018) found that technological innovation is an important factor affecting the transfer of polluting industries after studying the pollution-intensive industries in the Beijing-Tianjin-Hebei region. In addition, Li and Zhang (2018) believe that collusion between government and enterprises will accelerate the transfer of polluting industries, and the impact is increasing. Other scholars pointed out that social responsibility (Lambertini et al. 2016), policy orientation (Liu 2016), and fiscal decentralization (Yu et al. 2019) also have impact on the transfer of polluting industries.

To sum up, domestic and foreign scholars have conducted a lot of research on the transfer of pollution industry. However, due to the different environmental standards, sample selection, industrial data and research methods used by different studies, up to now, whether $\mathrm{PHH}$ exists is still in a heated debate. Secondly, when studying the transfer of polluting industries, economic, social, technological and other factors are highly valued, but there is generally a lack of consideration of the regional ecological environment carrying capacity. Whether the existing research results support $\mathrm{PHH}$ or deny $\mathrm{PHH}$, they generally default to 
the logic that the looser the environmental regulation, the worse the environmental quality of the area. This is reasonable to some extent, but the environmental quality is not only related to the environmental supervision of the government, but also closely related to the environmental capacity of the regional ecosystem. Therefore, the existing literature that ignores the ecological environment capacity is not complete, and it is not in line with the characteristics of the era of China's ecological civilization construction. Hence, this paper incorporates ecological carrying capacity into the factors analysis of polluting industries transfer. Then, the paper constructs a regression model to analyze the impact of different combinations of factors on pollution industry transfer based on the panel data of 30 provinces in China. This paper aims to reveal the real motivation of pollution industry transfer in China, and then provide decision-making ideas for the adjustment of industrial structure and the protection of ecological environment in China.

\section{Transfer Mechanism of Pollution Industry}

The transfer of pollution industry is not the result of a single factor according to the existing literature (Luo et al. 2014; Zhao et al. 2013). As socialism with Chinese characteristics enters a new era, especially after the 19th National Congress of the CPC, environmental protection has caused the unprecedented attention. Whether it is environmental regulation at the national level or the environmental supervision at various levels, both will bring increasing resistance to the transfer of pollution industry neglecting environmental factors. Therefore, based on the background of increasingly strict environmental regulation and the reality of the "one-vote veto system" of environmental protection in various regions, a Triangular Relation Model of China's pollution industry transfer is set up, in which three aspects: industrial advantage, location advantage and environmental advantage together.

\subsection{Industrial Advantage}

Industrial advantage, including technological advantages, scale advantages, auxiliary industry advantages and management advantages, are the basis of the transfer of pollution industry. Areas with industrial advantage are conducive to the development of pollution industry and can attract large numbers of pollution industry to settle in. The technological innovation, economic development level, industrial structure and preferential policies provided by the government for abstracting industrial investment would be considerated in this section.

\subsubsection{Technological Innovation.}

From the development trend of national and global environmental governance, absolute "environmental depressions" no longer exist. Many countries are strengthening environmental control and environmental standards. In China, the development strategy of "environmental priority" has been welcome in all ethnic groups across the country especially since the party's "Eighteenth National Congress" and "Nineteenth National Congress" were held. The "one-vote veto system for environmental protection" has been incorporated into the performance evaluation of local governments at all levels. Online monitoring of pollution sources Volatile Organic Compounds (VOC) has been fully installed, which makes the emission behavior of enterprises be recorded and tracked throughout the whole process. In this context, the transfer of pollution industry should tend to be "innovation highland" rather than "environment depression". Because new technology can not only improve the production efficiency and reduce production costs, but also help to solve the problems of carbon dioxide and other pollutants (Liu et al. 2019), environmental governance, etc., so that the pollution industry does not need large-scale transfer to avoid the environmental punishment of the government. Therefore, the technological innovation ability of a region is the key variable to attract industrial transfer.

3.1.2. The Level of Economic Development.

Economic development is closely related to regional environmental problems. In the early stage of reform and opening up, the eastern coastal regions took the lead in carrying out 
reform and opening up. With the rich and cheap labor and land resources, the Pearl River Delta and Yangtze River Delta have become important destinations for international industries transfer. These industries not only promote the rapid development of the local economy, but also bring great damage to the local environment. Therefore, the eastern region begins to raise the level of environmental control, strictly restrict the development of polluting industries, and force polluting industries to switch out. At the same time, the central and western regions of China have become an important place to undertake industrial transfer for the development of "economic priority". The gradient characteristics of industrial transfer are obvious between the eastern and western regions of China. In addition, the level of economic development usually means larger market size and more development potential. Therefore, in the view of investment environment and market demand, pollution industry prefers to transfer to the region with high level of economic development.

\subsubsection{Industrial Structure.}

The development of any industry is inseparable from the related industries or auxiliary industries. Therefore, there is a close relationship between industrial structure and the transfer of pollution industry (Dai et al. 2008). Generally speaking, the pollutant emissions are more in the areas where the secondary industry accounted for a significantly larger proportion than the third industry. From the economic development experience of advanced provinces and cities, the development mode is changing from extensive type to intensive type, and the industrial structure is optimizing and upgrading, which is highlighted by the steady expansion of the tertiary industry and the decline of the secondary industry. Therefore, the more developed the tertiary industry, the lower the transfer of pollution industry; the more developed the secondary industry, the higher the transfer of pollution industry.

\subsubsection{Preferential Policies of the Government.}

Due to historical, economic and natural reasons, the economic development of the central and western regions as a whole lag behind the eastern coastal provinces and cities. Therefore, the central and western regions have introduced government preferential policy measures in the new round of industrial development in the pursuit of catching up. Some scholars even pointed out that policy support is a direct factor for the industrial transfer (Xie et al. 2016), and the policy content covers a wide range of fields, such as preferential land use policies, tax incentives, financial support, research and development subsidies and green innovation compensation, green channels for administrative approval, etc. In addition, the government provides excellent talent intensive policies, housing bonus policies, etc. which will also promote the industrial transfer to some extent. In short, the above-mentioned series of preferential policies constitute a strong attraction for the polluting industry, and the polluting industries are more inclined to transfer to the regions with more preferential policies.

\subsection{Location Advantage}

Location advantage refer to the resource endowment of undertaking industry transfer, including human resources, natural resources, infrastructure, etc. It reflects the development foundation that the region can provide for undertaking industry. The labor cost, natural resources endowment, transportation infrastructure and other indicators are location advantages.

\subsubsection{Labor Cost.}

Labor cost is an important component of enterprise production costs, especially for labor-intensive industries, which generally choose to gather in areas with low labor cost (Zhang et al. 2013). Particularly domestic labor price has risen rapidly in recent years, so that labor cost accounts for an increasing proportion of the total cost. In order to reduce costs, enterprises began to transfer to the regions with low labor costs, especially the industrial enterprises with simple production technology and engaged in processing. Therefore, in order to maximize profits, enterprises generally give priority to industrial layout in areas with high population density and relatively low labor costs. 


\subsubsection{Natural Resource Endowment.}

Industrial development needs a large number of natural resources for a greater attraction to resource-based pollution industry. If an industrial enterprise is built in an area rich in natural resources, it can not only avoid the risk of shortage or even interruption of raw material supply, but also reduce the long-distance transportation cost of raw materials, so as to greatly reduce the risk of production and operation and improve the market supply. In other words, natural resource endowments play a positive role in the location selection of pollution industries (Aleksynska et al. 2013). In China, compared with the eastern region, the western region has a greater advantage in natural resources (Xue et al. 2019), which is more attractive for heavy industries with large demand for natural resources and less obvious demand for technology.

\subsubsection{Infrastructure Status.}

Infrastructure includes transportation, information transmission, financial and cultural services, etc. Good infrastructure can not only meet the needs of enterprise transportation of products and raw materials, but also be conducive to the formation of people flow, capital flow and information flow, and provide great development potential for industrial enterprises ( $\mathrm{Xu}$ et al. 2015). Therefore, the regional infrastructure is an important factor for the location choice of enterprises. With the rapid development of high-speed rail in China, the transportation network of "eight vertical and eight horizontal" has formed. After the "One Belt One Road" strategy, many China Europe railways are operating in the central and western regions, such as Zhengzhou, Chongqing and Wuhan city, which make the overseas trade of these regions more convenient than before (Tian et al. 2020). All these have created favorable conditions for industry transfers in.

\subsection{Environmental Advantage}

In the context of ecological civilization construction, environmental advantages are important strategic resources that are rare and difficult to replicate in a region. Environmental advantage includes government environmental regulation, public environmental awareness, and ecological environment capacity in this paper.

3.3.1. Government Environmental Regulation.

In the different economic and technological development stages, the national environmental standards are different. In order to save environmental costs, relatively developed countries or regions began to transfer out those industries with high pollution and emission, which brought a strong thrust to the transfer of pollution industry. At the same time, the less developed regions usually practice the development idea of "economic priority" in practices, provide development space for industries with good momentum of economic development and heavy pollution, and even provide them with "competitive environmental standards" (Deng et al. 2015), which objectively formed the pull to pollution industry. Under the dual effects of "thrust" and "pull", it is easy to cause polluting industries to transfer from region with strict environmental controls to the one with loose environmental controls.

\subsubsection{Public Environmental Awareness.}

Public awareness of environmental protection closely links to economics, science and humanities. In the developed areas, people's education level is generally higher, market competition is more intense, environmental information disclosure and public participation channels are more convenient, information exchange is more frequent, and the public's environmental awareness is relatively strong than that of the less developed. The concentrated expression is that the public pays more attention to the surrounding environment, has a deeper understanding of green products and environmental protection behaviors, and has a strong sense of environmental rights protection. Therefore, the living space of pollution industry here will be more constrained. In contrast, in areas where economic development is relatively backward, environmental education and publicity and environmental infrastructure construction are seriously lagging behind, making the overall 
public's environmental awareness weak, environmental protection concepts backward, insufficient awareness of environmental values, and supervision of environmental violations is greatly discounted, all of these provide favorable shelter for the settlement of pollution industries (Chen et al. 2015).

\subsubsection{Ecological Carrying Capacity.}

Eco-carrying capacity refers to the total area of bio-productive land that a region can provide. To some extent, it can reflect the ecological environment of a region, and it is the maximum loading that the natural environment can bear. Areas with lower ecological carrying capacity mean that the environmental capacity is relatively limited, the ecological sustainability is poor, and the self-healing ability of ecological function will even face the problem of worsening. Therefore, in order to achieve sustainable development, the economic and social values of the natural environment would be both fully valued. The local government has to formulate high standards for pollutant discharge compliance, increase environmental illegal costs and environmental transaction costs, tighten the issuance of carbon emission permits (Cheng et al. 2018), and set more environmental control measures, etc. This disguise is equivalent to raising the compliance costs of polluting enterprises and forcing polluting industries to transfer out.

In a word, industrial advantage is the basis of industrial transfer, location advantage is the endowment of resources to undertake industrial transfer, and environmental advantage is the external condition of industrial development. The three complements are complementary and indispensable. Therefore, this paper constructs a triangular relationship model of pollution industry transfer as shown in Figure 1.

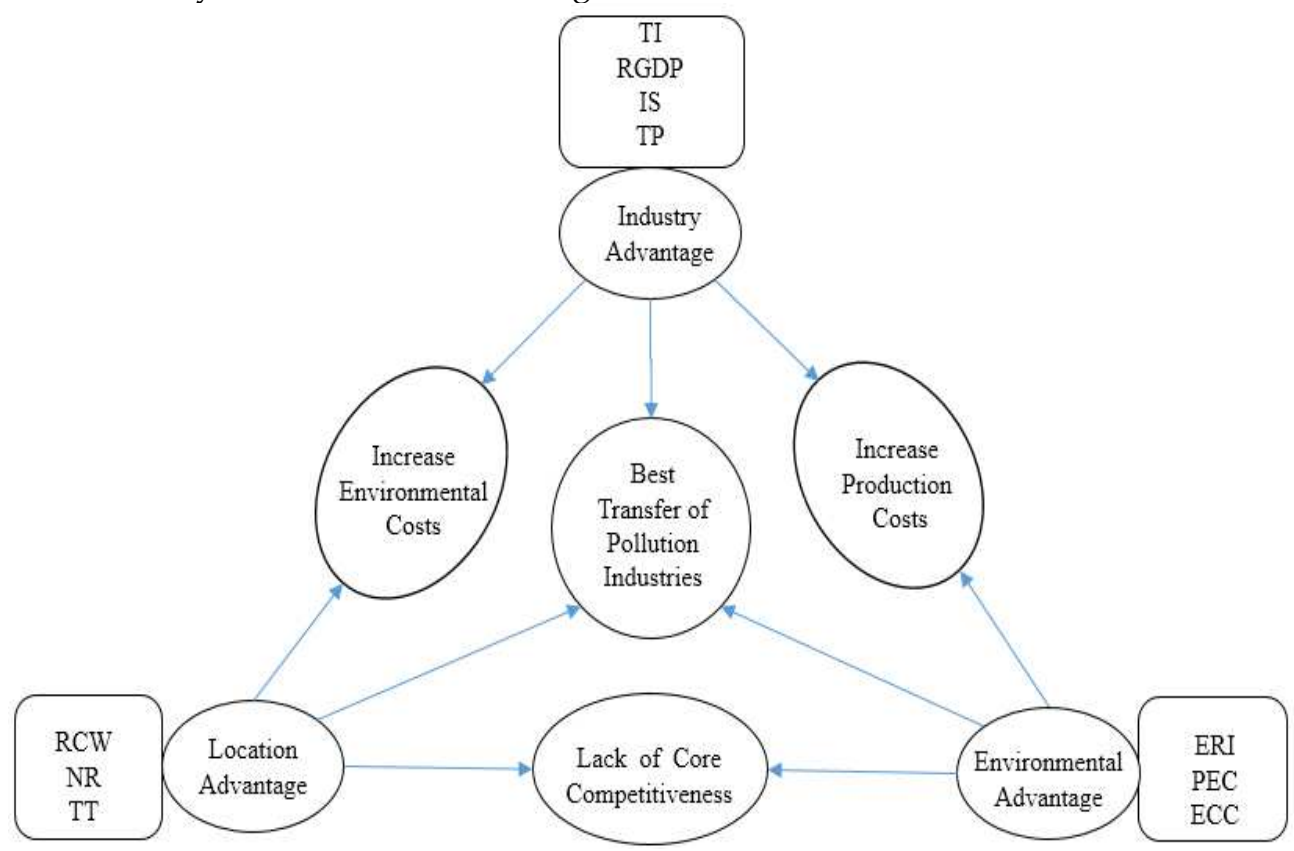

Figure. 1. Triangular Relationship Model of Pollution Industry Transfer.

\section{Research Methods and Data Sources}

\subsection{Variable Selection}

According to the theoretical analysis on the transfer mechanism of pollution industry, this paper selects 10 explanatory variables such as economic development level, industrial structure, transportation infrastructure, environmental regulation intensity and per capita ecological carrying capacity from three aspects: industry, location, and environment (Table 1).

Firstly, it is necessary to scientifically measure the amount of pollution industry transfer. The paper defined the polluting industry as follows (Wang et al. 2019): firstly, based on the industrial wastewater, waste gas, solid waste and $\mathrm{SO}_{2}$ emissions data and industrial sales output value data from 2006 to 2015 in China, the paper calculated the pollution emission 
intensity coefficient of 38 industries. Secondly the 38 industries in China are divided into four types: heavy, medium, light pollution industries and clean industries (clean industry is not the focus of this paper) according to the coefficient and various of pollution emission intensity between 2006-2010 and 2011-2015. Then, the top three ones of every type polluting industry are selected as the research objects in this paper. Specifically, the three industries as representative heavily polluting industries are paper products industry, ferrous metal smelting and calendaring industry, power thermal production and supply industry; the three representative moderate pollution industry are chemical raw materials and chemical products manufacturing industry, coal mining and washing industry, and non-metallic mineral products industry. The three representative industries selected as mild pollution industry are chemical fiber manufacturing, textile industry and food industry. The pollution industry transfer volume is defined as the proportion of the whole output values of 9 pollution industries in every province to the all value in China. Among them, the increase of $\mathrm{Y}$ indicates the polluting industries transfer in and the decrease of $\mathrm{Y}$ indicates the polluting industries transfer out.

Secondly, the indicator setting and calculation methods of most explanatory variables are shown in Table 1. This paper focuses on the introduction of the ecological carrying capacity index. The calculation method of per capita ecological carrying capacity index of various provinces or cities is: based on the data of cultivated land, forest land, grassland, construction land, water area and fossil energy land area of 30 provinces or cities in China from 2000 to 2015, the total ecological carrying capacity is calculated with the balance factor and yield factor. Then, $12 \%$ of the land is taken off for biodiversity conservation, and finally, the per capita ecological carrying capacity of each province over the years is obtained by dividing the total population of the region.

Table 1. Variable Symbol and Index Calculation.

\begin{tabular}{|c|c|c|c|}
\hline & Symbol & Influencing factor & Statistical indicators \\
\hline \multirow{5}{*}{ Industry } & Y & Explained variable & $\begin{array}{l}\text { The output value of the nine pollution } \\
\text { industries in every province/the output value } \\
\text { of the nine pollution industries in China (\%) }\end{array}$ \\
\hline & TI & Technology Innovation & $\begin{array}{l}\text { Internal expenditure of R\&D funds for } \\
\text { science and technology/ GDP of each } \\
\text { province in the current year }\end{array}$ \\
\hline & RGDP & Relative GDP & $\begin{array}{l}\text { Per capita GDP of each province/per capita } \\
\text { GDP of the whole country (\%) }\end{array}$ \\
\hline & IS & Industrial Structure & $\begin{array}{l}\text { Tertiary industry value added/Secondary } \\
\text { industry value added(\%) }\end{array}$ \\
\hline & $\mathrm{TP}$ & Tax Policy & $\begin{array}{c}\text { Regional tax revenue / total GDP of each } \\
\text { province }(\%)\end{array}$ \\
\hline \multirow[t]{3}{*}{ Location } & RCW & Relative Cost of Wage & $\begin{array}{l}\text { Average wages of employees in each } \\
\text { province/average wages of employees in the } \\
\text { country }(\%)\end{array}$ \\
\hline & NR & Natural Resources & $\begin{array}{l}\text { Number of practitioners/total practitioners in } \\
\text { regional extractive industries }(\%)\end{array}$ \\
\hline & TT & Total Transportation & $\begin{array}{c}\text { Total Mileage (Highway + Railway + Inland } \\
\text { River Shipping)/the total Area of each } \\
\text { province }(\%)\end{array}$ \\
\hline \multirow[t]{3}{*}{ Environment } & ERI & $\begin{array}{l}\text { Environmental } \\
\text { Regulation Intensity }\end{array}$ & $\begin{array}{l}\text { Unit pollution control cost of each province } \\
\text { /Unit pollution control cost in China (\%) }\end{array}$ \\
\hline & PEC & $\begin{array}{l}\text { Public Environmental } \\
\text { Consciousness }\end{array}$ & $\begin{array}{l}\text { Number of students in ordinary colleges and } \\
\text { universities per } 10,000 \text { people (number) }\end{array}$ \\
\hline & ECC & $\begin{array}{l}\text { Ecological Carrying } \\
\text { Capacity }\end{array}$ & $\begin{array}{l}\text { Ecological carrying capacity per capita } \\
\text { (gha/ per capita) }\end{array}$ \\
\hline
\end{tabular}
(gha/ per capita) 
China (excluding Tibet, Hong Kong, Macao and Taiwan) in 2000-2015 are from the annual China Statistical Yearbook, China Industrial Statistical Yearbook, China Environmental Statistical Yearbook, China Science and Technology Statistical Yearbook, China Population and Employment Statistical Yearbook. In addition, this paper uses industrial sales value instead because of the incomplete data of industrial output value in individual years, and the difference between industrial sales value and industrial output value is negligible. When calculating the per capita ecological carrying capacity index, this article refers to the equilibrium factors from the annual report of World Wildlife Fund (WWF) in 2016, the yield factor from the common research literature (Zheng et al. 2013), the productive land area from the Chinese Statistical Yearbook, Chinese Energy Statistical Yearbook, the website of the State Forestry Administration and the National Bureau of Statistics, China's Social and Economic Development Statistical Database and the United Nations Food and Agriculture Organization Database. The above statistical data are generally coherent in general.

\subsection{Model Construction}

Based on the panel data of 30 provinces or cities in China from 2000 to 2015, this paper separately makes an empirical study on the four combined models of "industry + location", "location + environment", "industry + location + environment". In order to eliminate the heteroscedasticity, this paper takes the logarithm of the explained variable and the explained variable.

$$
\begin{aligned}
\ln Y_{i t} & =a_{0}+\alpha_{1} \ln T I_{i t}+\alpha_{2} \ln R G D P_{i t}+\alpha_{3} \ln I S_{i t}+\alpha_{4} \ln T P_{i t} \\
& +\alpha_{5} \ln R C W_{i t}+\alpha_{6} \ln N R_{i t}+\alpha_{7} \ln T T_{i t}+\mu_{1 i t}
\end{aligned}
$$

$$
\begin{gathered}
\quad+\beta_{5} \ln P E C_{i t}+\beta_{6} \ln E C C_{i t}+\mu_{2 i t} \\
\ln Y_{i t}=c_{0}+\gamma_{1} \ln T I_{i t}+\gamma_{2} \ln R G D P_{i t}+\gamma_{3} \ln I S_{i t}+\gamma_{4} \ln T P_{i t}
\end{gathered}
$$$$
+\gamma_{5} \ln E R I_{i t}+\gamma_{6} \ln P E C_{i t}+\gamma_{7} \ln E C C_{i t}+\mu_{3 i t}
$$$$
\ln Y_{i t}=d_{0}+\delta_{1} \ln T I_{i t}+\delta_{2} \ln R G D P_{i t}+\delta_{3} \ln I S_{i t}+\delta_{4} \ln T P_{i t}
$$$$
+\delta_{5} \ln R C W_{i t}+\delta_{6} \ln N R_{i t}+\delta_{7} \ln T T_{i t}+\delta_{8} \ln E R I_{i t}
$$$$
+\delta_{9} \ln P E C_{i t}+\delta_{10} \ln E C C_{i t}+\mu_{4 i t}
$$

Here: $i$ indicates province, $t$ represents year, $a_{0} 、 b_{0} 、 c_{0} 、 d_{0}$ is the common intercept, $\alpha_{i}, \beta_{i} 、 \gamma_{i}, \delta_{i}$ refer to the regression coefficient of each independent variable, $\mu_{i t}$ is a random disturbance term.

\section{Empirical Research}

\subsection{Statistical Test}

Firstly, this paper carries out descriptive statistics for all variables, and the results are seen in Table 2.

Table 2. Descriptive Statistics of Each Variable.

\begin{tabular}{ccccccc}
\hline variable & mean & SD & p50 & min & $\max$ & $\mathrm{N}$ \\
\hline $\mathrm{Y}$ & 0.740 & 1.030 & 0.780 & -1.770 & 2.660 & 480 \\
$\ln T I$ & -1.540 & 0.970 & -1.670 & -3.310 & 1.460 & 480 \\
$\ln R G D P$ & 4.580 & 0.480 & 4.450 & 3.550 & 5.900 & 480 \\
$\ln I S$ & 4.500 & 0.320 & 4.460 & 4.000 & 5.800 & 480 \\
$\ln T P$ & 2.130 & 0.310 & 2.110 & 1.580 & 2.940 & 480 \\
$\ln R C W$ & 4.560 & 0.230 & 4.490 & 4.290 & 5.270 & 480 \\
$\ln N R$ & 1.040 & 1.340 & 1.440 & -4.020 & 3.040 & 480 \\
$\ln T T$ & 3.980 & 0.900 & 4.070 & 1.270 & 5.460 & 480 \\
$\ln E R I$ & 4.760 & 0.950 & 4.670 & 2.620 & 7.000 & 480 \\
$\ln P E C$ & 0.160 & 0.630 & 0.300 & -1.490 & 1.210 & 480
\end{tabular}




\begin{tabular}{|c|c|c|c|c|c|c|c|c|c|c|c|}
\hline \multirow[b]{2}{*}{398} & \multicolumn{2}{|c|}{$\ln E C C$} & 0.750 & \multicolumn{2}{|c|}{0.610} & 0.580 & 0.06 & \multicolumn{2}{|c|}{3.090} & 480 & \\
\hline & \multicolumn{10}{|c|}{ Note: all calculation work is done on stata15 software, the same below. } & \\
\hline 399 & \multirow{2}{*}{\multicolumn{11}{|c|}{$\begin{array}{l}\text { Combined with the almost equal relationship between the median and the average, the } \\
\text { differences between provinces all variables are small and the overall discreteness is small. In }\end{array}$}} \\
\hline 400 & & & & & & & & & & & \\
\hline 401 & \multicolumn{11}{|c|}{ terms of standard deviation, except for industry transfer $(\mathrm{Y})$ and natural resource endowment } \\
\hline 402 & \\
\hline 403 & \multicolumn{11}{|c|}{ research sample is suitable for further analysis. Next, this paper conducts a correlation } \\
\hline 404 & \multicolumn{11}{|c|}{ analysis, and the results are shown in Table 3 . It can be seen that, the overall absolute value is } \\
\hline 405 & \multirow{3}{*}{\multicolumn{11}{|c|}{$\begin{array}{l}\text { below } 0.5 \text {, whether it is Pearson's correlation coefficient or Spearman's correlation coefficient, } \\
\text { from which we can see that there is no serious collinearity among the variables, so it is } \\
\text { suitable for next regression analysis. }\end{array}$}} \\
\hline 406 & & & & & & & & & & & \\
\hline 407 & & & & & & & & & & & \\
\hline \multirow[t]{2}{*}{408} & \multicolumn{11}{|c|}{ Table 3. Correlation Analysis of Variables. } \\
\hline & Y & $\ln E R I$ & $\ln R G D P$ & $\ln R C W$ & $\ln I S$ & $\ln N R$ & $\ln T P$ & $\ln P E C$ & $\ln T T$ & $\ln E C C$ & $\ln T I$ \\
\hline$Y$ & & $59^{* * * *}$ & $0.530^{* * * *}$ & $0.229^{* * * *}$ & 0 & -0.16 & $\begin{array}{l}-0.09 \\
\end{array}$ & $0.130^{* * * *}$ & $0.506^{* * * *}$ & $-0.603^{* * *+}$ & $-0.081^{*}$ \\
\hline १ERI & $-0.250^{* * * * *}$ & & 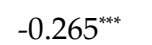 & $-0.149^{* * * *}$ & -0. & & $0.200^{* * * *}$ & $0.147^{* * * * *}$ & $-0.075^{*}$ & $0.311^{* * * * *}$ & $-0.262^{* * * *}$ \\
\hline RGDP & $0.470^{* * * *}$ & $-0.323^{* * * * 4}$ & & $0.623^{* * * *}$ & & & 0.2 & & & & \\
\hline $\mathrm{RCV}$ & $0.216^{* * * *}$ & & $0.806^{* * * *}$ & & 0.11 & & 0.4 & 0.2 & & & \\
\hline $\mathrm{n} I S$ & $-0.340^{* * * * *}$ & & $0.188^{* * * *}$ & $0.416^{* * *}$ & & -0.37 & 0.20 & & & & $0.288^{* * * *}$ \\
\hline $\mathrm{n} N R$ & $-0.203^{* * * *}$ & & -0.57 & $-0.674^{* * *+1}$ & -0.41 & & -0.2 & -0.2 & & & -0.053 \\
\hline 111 & $-0.118^{* * * *}$ & & & $0.524^{* * * * *}$ & $0.423^{* \ldots * *}$ & $-0.426^{* * * *}$ & & $0.628^{* * * * *}$ & & & $-0.107^{* * *}$ \\
\hline $\mathrm{n} P E C$ & $0.096^{* *}$ & & & $0.326^{* * * *}$ & & -0.2 & $0.597^{* * * *}$ & & $0.650^{* * *+*}$ & $-0.390^{* * * *}$ & 0.013 \\
\hline $\ln T T$ & $0.510^{* * * *}$ & -0.073 & $0.419^{* * * * *}$ & $0.323^{* * * *}$ & $0.087^{*}$ & $-0.437^{*+4 x}$ & $0.435^{* * * *}$ & $0.544^{* * * *}$ & & $-0.725^{* * * *}$ & $-0.084^{*}$ \\
\hline $\mathrm{n} E C C$ & $-0.436^{* * * *}$ & $0.318^{* * * *}$ & $-0.646^{* * *+*}$ & $-0.680^{* * * *}$ & $-0.351^{* * * *}$ & $0.653^{* * * *}$ & $-0.395^{* * * *}$ & $-0.368^{* * * *}$ & $-0.741^{* * * * *}$ & & $-0.196^{* * * *}$ \\
\hline רTI & -0.044 & $-0.251^{* * * *}$ & $0.192^{* * * *}$ & $0.344^{* * * *}$ & $0.448^{* * * *}$ & $-0.148^{* * * *}$ & 0.061 & 0.054 & 0.014 & $-0.399^{* * * * *}$ & \\
\hline
\end{tabular}

409 Note: the upper triangle is Pearson's correlation coefficient, the lower triangle is

410 Spearman's correlation coefficient; ${ }^{* *} \mathrm{P}<0.01,{ }^{* *} \mathrm{P}<0.05,{ }^{*} \mathrm{P}<0.1$.

411 5.2. Results Analysis

412 In this paper, regression analysis is carried out for four combination models, and the 413 detailed results are shown in Table 4.

414

Table 4. Regression Results of Different Combination Models.

\begin{tabular}{ccccc}
\hline Variable & Model 1 & Model 2 & Model 3 & Model 4 \\
\hline \multirow{2}{*}{$\ln T I$} & 0.034 & & $0.076^{*}$ & $0.179^{* * *}$ \\
& $(0.91)$ & & $(1.74)$ & $(4.35)$ \\
$\ln R G D P$ & $0.818^{* * *}$ & & $1.368^{* * *}$ & $1.311^{* * *}$ \\
& $(7.38)$ & & $(14.44)$ & $(10.13)$ \\
$\ln I S$ & $-1.300^{* * *}$ & & $-1.349^{* * *}$ & $-1.322^{* * *}$ \\
& $(-10.36)$ & & $(-10.48)$ & $(-11.12)$ \\
$\ln T P$ & $-1.171^{* * *}$ & & $-0.998^{* * *}$ & $-1.010^{* * *}$ \\
& $(-6.00)$ & & $(-5.64)$ & $(-5.29)$ \\
$\ln R C W$ & 0.266 & $0.504^{* *}$ & & -0.197 \\
& $(0.88)$ & $(2.05)$ & & $(-0.64)$ \\
$\ln N R$ & -0.017 & $0.133^{* * *}$ & & -0.004 \\
& $(-0.54)$ & $(3.02)$ & & $(-0.13)$ \\
$\ln T T$ & $0.637^{* * *}$ & $0.936^{* * *}$ & & $0.742^{* * *}$ \\
& $(15.66)$ & $(10.22)$ & & $(11.03)$ \\
$\ln E R I$ & & $-0.231^{* * *}$ & $-0.085^{*}$ & 0.045 \\
& & $(-3.42)$ & $(-1.66)$ & $(0.90)$ \\
$\ln P E C$ & $-0.242^{* *}$ & $-0.530^{* * *}$ & $-0.687^{* * *}$ \\
& & $(-2.33)$ & $(-5.38)$ & $(-7.50)$ \\
$\ln E C C$ & $-0.308^{* * *}$ & $-0.678^{* * *}$ & 0.070 \\
& & $(2.68)$ & $(-12.42)$ & $(0.82)$ \\
\hline
\end{tabular}




\begin{tabular}{ccccc}
\hline \multirow{2}{*}{ Hausman test } & 128.68 & 44.80 & 105.15 & 106.53 \\
& $(0.00)$ & $(0.00)$ & $(0.00)$ & $(0.00)$ \\
_cons & -1.674 & $-4.515^{* * *}$ & $-3.797^{* * *}$ & 0.911 \\
& $(1.53)$ & $(-3.53)$ & $(5.24)$ & $(0.84)$ \\
N & 480 & 480 & 480 & 480 \\
r2_a & 0.647 & 0.341 & 0.599 & 0.685 \\
\hline
\end{tabular}

Note: the regression coefficient is $\mathrm{t}$ statistic in brackets. Hausman tests that the number in brackets is the value of prob $>$ F. Hausman test is used to determine whether fixed effect model or random effect model would be adopted in the process of empirical test. From the $p$ value of each model, the original hypothesis is rejected, so fixed effect regression model should be established.

\subsubsection{The Impact of Industrial Factors + Location Factors}

(1) In Table 4, the results of Model 1 reflect the influence of industrial factors + location factors on the pollution industry transfer. As is seen that the economic development, industrial structure and government preferential policies in the industrial factors have significant impact on the transfer of polluting industries, and the technological innovation factors fail to pass the significance test; while among the location factors, only transportation infrastructure has a significant impact on the transfer of polluting industries, and the labor cost and natural resource endowment fail to pass the significance test. The combination of the two further highlights the significant impact of industrial advantage on the transfer of polluting industries, which shows that the previous argument that industrial advantage is the basic factor of industrial transfer is reasonable. On the one hand, there is no significant difference in the level of technological innovation between provinces in China (the descriptive statistical results of technological innovation reflect that the degree of dispersion between provinces is not obvious), and the "innovation highland" with significant technological advantages has not yet formed; on the other hand, the driving force of technological innovation for industrial development is not outstanding, which makes it less attractive to industrial transfer. In addition, the relative labor cost in the location factor is not significant, which is consistent with the research results of Luo (2017), which is because the regional labor cost advantage is weakened for convenient transportation and large labor flow at this stage. The influence of natural resource endowments on the pollution industries transfer is not significant, as may be that seven of the nine pollution industries selected in this paper are general manufacturing industries, which are indirectly related to the development of mineral resources rather than directly related.

It can be seen from Model 1 that regions with industrial advantages and location advantages have an industrial foundation for attracting industries to transfer in, and at the same time, they can greatly reduce the transportation costs and the operating costs of enterprises. However, due to the lack of consideration of environmental issues, if the increased environmental cost is far greater than the cost of transportation cost savings, not only the region could not fundamentally reduce the production cost of the enterprise, but also face the risk of "being closed", "stop" and "being limited production", so that the pollution industry wouldn't transfer in.

\subsubsection{The impact of Location Factors + Environmental Factors}

(2) In Table 4, the results of Model 2 reflect the influence of location factors + environmental factors on the polluting industries transfer. From the results, three variables in the location factors and three variables in the environment factors have significant influence on the transfer of pollution industry, and the location factors have a positive role and the environment factors have a negative role. This result confirms the starting point of this paper, that is, the new era should attach great importance to the impact of ecological environment on industrial transfer. Further from the regression coefficients, it can be seen that infrastructure and labor costs have the greatest impact, which is in line with the 
above-mentioned location advantage is the resource endowment to undertake pollution industry development, and the environmental advantage is the external conditions for industrial development. It is worth noting that the regions with large per capita ecological carrying capacity do not increase the opportunities for pollution industry transfer as expected, but suppress the transfer of pollution industries. The possible reason is that the regions with low per capita ecological capacity are often those with high population density and highly developed economies. For example, in 2015, Guangdong, Beijing, and Shanghai were the three provinces and cities with the lowest per capita ecological capacity $(0.253,0.086,0.054$ global hectares / person, respectively), while Inner Mongolia, Qinghai, and Heilongjiang are the three provinces and cities with the highest per capita ecological carrying capacity (3.111, 2.289, and 1.681 global hectares / person, respectively). The former is strictly controlled in terms of environmental control and transfer of polluting industries. In addition, this result also reflects that the transfer of pollution industry in China is mainly affected by economic development and supporting industrial base, and environmental factors have not yet played a strategic role.

Model 2 shows that regions with regional and environmental advantages are very attractive for enterprises to increase profits and reduce production and operation costs. Comparing the $\mathrm{R}^{2}$ of Model 2 and Models 1 and 3, it can be found that this combined model misses important variables in explaining industrial transfer. From this, it can be concluded that the core and key of industrial development mainly depend on the developed and complete industrial chain foundation. To some extent, the regions that lack of industrial advantages mean lacking the core competitiveness to attract industrial transfer to this point. 5.2.3 The Impact of Industrial Factors + Environmental Factors

(3) In Table 4, the results of Model 3 reflect the influence of industrial factors + environmental factors on the transfer of polluting industries. The regression results show that most indicators have passed the significance test. The test results of industrial factors are basically the same as those in Model 1, and the test results of environmental factors are basically the same as those in Model 2. This shows that the mechanism analysis in this article is relatively reasonable. The economically developed regions have a certain industrial economic foundation, which can promote industrial development and provide industrial support for the transfer of polluting industries to the region. At the same time, with the continuous strengthening of environmental control intensity and public awareness of environmental protection, the development of pollution industry will be restricted by environmental factors, which basically coincides with the law of the transfer of pollution industry in China.

Model 3 shows that regions with both industrial and environmental advantages can reduce operating costs such as enterprise taxes and environmental costs. Enterprises can understand market demand and development potential through the industrial structure and economic development level of a region, and provide reference for the transfer of polluting industries. However, due to the lack of location advantages, it may increase the production and operation costs of labor and transportation of the enterprise, which may eventually make the industrial development fall into a dilemma. Therefore, areas with only industrial and environmental advantages and no location advantages are beneficial to the development of some pollution industries, but for labor-intensive industries or resource intensive industries, location factors will hinder the transfer of such pollution industries.

\subsubsection{The Impact of Industrial Factors + Location Factors + Environmental Factors}

(4) In Table 4, the results of Model 4 reflect the influence of industrial factors + location factors + environmental factors on the transfer of polluting industries. It can be seen that technological innovation, economic development level, industrial structure and government preferential policies in industrial advantages have a significant impact on the transfer of polluting industries, while only public environmental awareness and traffic facilities have a 
significant impact on the transfer of polluting industries in environmental factors and location factors. The combination of the three shows that industrial advantage is the foundation of industrial development and the first condition for considering the transfer of pollution industry. The location factor is not significant in the overall regression results of the three factors, which may be the implementation of the national regional coordinated development strategy at this stage, greatly reducing the imbalance between regions. (4) From the regression coefficients, economic development and infrastructure are the two most prominent positive factors, and industrial structure, taxation policies and public environmental awareness are the three most prominent negative factors, which is consistent with the test results of (1), (2) and (3) as a whole. In addition, the factors of environmental control intensity fail to pass the significance test, which may be related to the timeliness of environmental control policies. This study is all the data of that year, and the practical effect of environmental control policies often has a certain time lag effect, which also has a certain impact on the later pollution control investment.

\subsection{Robustness Test}

In order to test the validity of the model, this paper uses a sampling test (at random $80 \%$ of the total number of samples) to conduct a robustness analysis. The results show that the degree of significance of the indicator is the same as that of the model 4 , indicating that the overall passed the robustness test and the regression result is effective.

In addition, in order to further examine how the environmental factors have affected the transfer of polluting industries since the 18th National Congress of the Communist Party of China. This paper divides the research area into 2000-2011 and 2012-2015 based on the 2012 held at the 18th National Congress of the Communist Party of China. Four scenarios of industry + location, location + environment, industry + environment, industry + location + environment were again tested, and the fixed-effect model can still be used. The results are shown in Table 5.

Firstly, it can be seen that the overall goodness of fit of the model through the overall $\mathrm{R}^{2}$ of the model. The results of both the inter regional test and the overall research period show that the model has good stability, indicating that the triangle model can better explain the important factors affecting the transfer of pollution industry. Secondly, comparing model (4) with models (1), (2), and (3) respectively, it can still be concluded that industry is the basic factor affecting the pollution industry transfer, and the importance of location and environmental factors is much weaker than that of industrial factors, which shows that the analysis of various factors in the original triangle model is objective and the model has good robustness. Finally, although the importance of environmental factors is less than that of industry as a whole, the government's environmental regulation, the public's environmental awareness and the per capita ecological carrying capacity of natural conditions have almost shown an obvious trend of enhancement since the 18th National Congress of the Communist Party of China. Which once again confirmed the point raised in this article that environmental factor will play an increasingly important role in the transfer of China's polluting industries in the context of ecological civilization construction.

Table 5. Regression Results Under Different Combination Models in 2012-2015.

\begin{tabular}{|c|c|c|c|c|}
\hline Variable & Model(1) & Model(2) & Model(3) & Model(4) \\
\hline \multirow{2}{*}{$\ln T I$} & -0.026 & & -0.020 & 0.041 \\
\hline & $(-0.36)$ & & $(-0.27)$ & $(0.55)$ \\
\hline \multirow{2}{*}{$\operatorname{lnRGDP}$} & $0.891^{* * *}$ & & $1.219^{* * *}$ & $1.292^{* * *}$ \\
\hline & (3.62) & & $(6.83)$ & $(4.87)$ \\
\hline $\operatorname{lnIS}$ & $\begin{array}{c}-0.880^{* * *} \\
(-3.95)\end{array}$ & & $\begin{array}{c}-0.884^{* * *} \\
(-3.9)\end{array}$ & $\begin{array}{c}-0.823^{* * *} \\
(-3.88)\end{array}$ \\
\hline $\operatorname{lnTP}$ & $\begin{array}{c}-1.656^{* * *} \\
(-4.30)\end{array}$ & & $\begin{array}{c}-1.348^{* * *} \\
(-4.18)\end{array}$ & $\begin{array}{c}-1.180^{* * *} \\
(-3.06)\end{array}$ \\
\hline
\end{tabular}




\begin{tabular}{|c|c|c|c|c|}
\hline $\operatorname{lnRCW}$ & $\begin{array}{l}0.643 \\
(0.87)\end{array}$ & $\begin{array}{l}-0.580 \\
(-1.26)\end{array}$ & & $\begin{array}{l}-0.173 \\
(-0.23)\end{array}$ \\
\hline $\operatorname{lnNR}$ & $\begin{array}{l}0.037 \\
(0.77)\end{array}$ & $\begin{array}{l}0.044 \\
(0.69)\end{array}$ & & $\begin{array}{l}0.074 \\
(1.51)\end{array}$ \\
\hline $\operatorname{lnTT}$ & $\begin{array}{c}0.694^{* * *} \\
(8.86)\end{array}$ & $\begin{array}{c}0.897^{* * *} \\
(4.69)\end{array}$ & & $\begin{array}{c}0.726^{* * *} \\
(5.16)\end{array}$ \\
\hline $\operatorname{lnERI}$ & & $\begin{array}{c}-0.405^{* * *} \\
(-3.46)\end{array}$ & $\begin{array}{c}-0.231^{* *} \\
(-2.50)\end{array}$ & $\begin{array}{l}-0.128 \\
(-1.42)\end{array}$ \\
\hline $\operatorname{lnPEC}$ & & $\begin{array}{c}-0.504^{* *} \\
(-2.28)\end{array}$ & $\begin{array}{c}-0.496^{* * *} \\
(-2.67)\end{array}$ & $\begin{array}{c}-0.687^{* * *} \\
(-3.82)\end{array}$ \\
\hline $\operatorname{lnECC}$ & & $\begin{array}{l}0.377^{*} \\
(1.70)\end{array}$ & $\begin{array}{c}-0.639^{* * *} \\
(-6.06)\end{array}$ & $\begin{array}{l}0.009 \\
(0.05)\end{array}$ \\
\hline Hausman test & $\begin{array}{c}33.25 \\
0.00\end{array}$ & $\begin{array}{c}13.76 \\
0.00\end{array}$ & $\begin{array}{c}28.11 \\
0.00\end{array}$ & $\begin{array}{c}27.58 \\
0.00\end{array}$ \\
\hline _cons & $\begin{array}{l}-1.342 \\
(-0.59)\end{array}$ & $\begin{array}{l}1.422 \\
(0.58)\end{array}$ & $\begin{array}{c}4.289^{* * *} \\
(3.69)\end{array}$ & $\begin{array}{l}0.071 \\
(0.03)\end{array}$ \\
\hline $\mathrm{N}$ & 120 & 120 & 120 & 120 \\
\hline r2_a & 0.652 & 0.382 & 0.611 & 0.688 \\
\hline
\end{tabular}

\section{Conclusions and Suggestions}

In order to analyze the transfer mechanism of China's polluting industries in the new period, this paper constructs a triangular model of pollution industry transfer from three aspects of industry, location and environment, and performs regression analysis of different combination models based on data from 2000-2015 in 30 provinces and cities across the country.

\subsection{Conclusions}

(1) Pollution industry transfer is a spatial migration activity based on the change of regional competitive advantage. During the research period, industrial advantage is the primary factor to be considered in the transfer of pollution industry in China, and the significance of location and environmental indicators is significantly lower than that of industrial indicators; (2) In particular, the level of economic development can positively attract industries to settle in. The more complete the infrastructure, the more conducive to successfully attracting industrial transfers, that is, areas with good economic foundations and convenient transportation are often the first place for industrial transfers, in other words, the industrial foundation and location factors are indeed attractive in the investment attraction. While the increase in public awareness of environmental protection and the strengthening of environmental control negatively affect the transfer of polluting industries. It shows that on the one hand, strengthening environmental management will force polluting industries to move out; on the other hand, reducing environmental standards will help attract polluting industries to move in. This is rather consistent with the fact that developed provinces in the east have issued industrial withdrawal lists and the central and western regions are competing to increase industrial acceptance. (3) Empirical research based on 30 provinces and cities in China also found that inter-provincial transfers have a tendency for polluting industries to take the transfer route to circumvent environmental regulation, and that technological innovation is not attractive enough for industrial transfers. The results show that there is a great possibility of $\mathrm{PHH}$ in the transfer of pollution industry between provinces in China, and there is a certain gap between the transfer of pollution industry and industrial transformation and upgrading in China. (4) From the perspective of development process, with the in-depth promotion of regional coordinated development strategy in China, the regional advantage difference between provinces will continue to narrow, which leads to the decline of the importance of location factors. At the same time, with the continuous increase of ecological civilization construction at the national level, the competitive advantage of 
environmental factors is increasing.

\subsection{Suggestions}

Combined with the above research results, this paper puts forward the following policy recommendations. First, local governments should continue to adhere to the development strategy of "environment first", never "environmental damage" due to "industrial investment", and implement the green development concept of "Green mountains and clear water are equal to mountains of gold and silver" in the process of undertaking industrial transfer. Second, local governments should strengthen environmental control and encourage green technology innovation, and both of them should be combined to force polluting enterprises to withdraw and improve their technological innovation ability, suppressing the inter-provincial migration of environmental pollution at the source, and finally realize the integration of industrial transfer and industrial transformation and upgrading. Third, local governments should strengthen the openness of data information and transparency in policy formulation, so that enterprises can obtain real-time and accurate information on regional economic development, human capital, and environmental quality, clarify the direction and advantages of local industrial development, help enterprises to make scientific location selection from the perspective of sustainable development, and promote the deep integration of digital industries such as big data and the Internet with real industries. At the same time, raise public awareness of environmental protection, fully mobilize the public's initiative to participate in ecological environmental governance, and strive to create a high-quality business environment.

\section{Author Contributions}

Formal analysis, Supervision, Writing - review \& editing, Liping Wang; Data curation, Resources, Writing - original draft, Wenjing Xia; Conceptualization, Methodology, Writing review \& editing, Chuang $\mathrm{Li}$

\section{Funding}

The research is supported by National Social Science Fund of China (19BJY086), Social Science Planning Project of Fujian Province (FJ2020B112), Educational Research Project of Young and Middle-aged Teachers in Fujian Province (Social Science, JAS20151).

\section{Data availability}

The datasets used and/or analyzed during the current study are available from the corresponding author on reasonable request.

\section{Compliance with ethical standards \\ Conflict of interest}

The authors declare that there is no conflict of interests.

\section{Ethical approval}

This study conforms to the ethical and moral requirements.

\section{Consent to participate}

All the authors of this article were consented to participate.

\section{Consent to publish}

This study was consented to be published.

\section{References}

Aleksynska, M.; Havrylchyk, O. "FDI from the South: the role of institutional distance and natural resources". Eur. J. Polit. Econ. 2013, 29, 38-53.

Chen, F.; Zhou, M. Does National Undertaking Industrial Transfer Demonstration Areas Aggravate Regional Environmental Pollution. J. Shanxi. Univ. Financ. Econ.2019, 10, 42-54. Cheng, Ai.; Zhao, F. Quantitative measure on inter-regional industry transfer and pollution transfer based on the idea of shift share analysis. China. Population. Resour. Environ. 2018, 28, 49-57.

Cheng, Z.; Li, L.; Liu, J. The emissions reduction effect and technical progress effect of environmental regulation policy tools. J. Clean Prod. 2017, 149,191-205.

D'Agostino, L.M. How MNEs respond to environmental regulation: integrating the Porter 
hypothesis and the pollution haven hypothesis. Econ. Polit. 2015, 32, 1-25.

Dai, H.; Wang, Y. An analysis of the relationship between industrial transfer and the adjustment of regional industrial structure. Contemp. Financ. Econ. 2008,2,293-98.

Deng,H.; Sang, B. Fiscal decentralization, environmental regulation and FDI competition among local governments. J. Shanghai. Univ. Financ. Econ.2015, 17, 79-88.

Dou, J.; Han, X. How does the industry mobility affect pollution industry transfer in China: Empirical test on Pollution Haven Hypothesis and Porter Hypothesis. J. Clean Prod. 2019, 01, 105-115.

Duan, J.; Wen, Y. Transfer and determinants of pollution-intensive industries in mega-metropolitan agglomerations: A case study of Beijing, Tianjin and Hebei. J. Southwest. Minzu. Univ. 2018, 2, 127-136.

$\mathrm{Gu}$, B.; Zhu, F. Research on the motive of regional transfer of pollution intensive industries and the influencing factors of location choice in China. Soc. Sci. Yunnan. 2013, 3, 66-70.

Guan, A. Economic agglomeration, tax competition and Inter regional industrial transfer. Macroeconomics 2018, 4, 48-53.

Jaffe, A. B.; Peterson, S. R.; Portney, P.R.; Stavins, R. N. Environmental Regulations and the Competitiveness of U.S. Manufacturing: What Does the Evidence Tell Us? J. Econ. Lit. 1995, 33,132-163.

Jeppesen, T.; List, J. A.; Folmer, H. Environmental regulations and new plant location decisions: evidence from a Metra-analysis. J. Regional Sci. 2002, 42, 19-49.

Kubicova. J. Testing greenhouse gasses in Slovakia for environmental Kuznets curve and pollution haven hypothesis. J. Int. Stud. 2014, 7, 161-177.

Lambertini L., Palestini A., Tampieri A. CSR in an asymmetric duopoly with environmental externality. South. Econ. J. 2016, 83, 236-252.

Levinson, A. Environmental regulations and manufacturers' location choices: Evidence from the Census of Manufactures. J. Public Econ. 1996, 62, 5-29.

Levinson, A. Environmental regulations and manufacturers' location choices: Evidence from the Census of Manufactures. J. Public Econ. 1996, 62,5-29.

Li, B.; Zhang, X. Theoretical and Empirical Analysis of Environmental Pollution Transfer in China from the Perspective of Collusion between Government and Enterprises. J. Cent. Univ. Financ. Econ. 2018, 5, 72-81.

Li, G.; Du, S. Influence of environmental regulation on spatial distribution of pollution industry. Jianghan Acad. 2018, 37, 49-55.

Li, M.; Ma, M. Research on Industry Selection and Layout Optimization of Industry Transfer in Beijing-Tianjin-Hebei. Econ. Probl. 2016, 1, 124-128.

Liang, H.; Wang, J.; Qin, Z.; et al. Research on the Transfer of Pollution-Intensive Industries in China and Its Influencing Factors. Ecol. Economy, 2016, 32, 32-35.

Liu, J.; Yang, Q.; Zhang, Y.; et al. Analysis of CO2 Emissions in China's Manufacturing Industry Based on Extended Logarithmic Mean Division Index Decomposition. Sustainability 2019, 11(1), 226.

Liu, Y. Industrial Resettlement and Environmental Pollution in Guangdong Province: An Empirical Study on Twenty-one Prefecture-level Cities by DID. Ind. Econ. Rev. 2016, 4, 91-106. Luo, H.; Miao, C; Li, G. Review on empirical research and related controversies of different regional Scale industrial transfer. Hum. Geogr. 2014, 2, 1-8.

Luo, Y. The Impact of Regional Environmental Regulation on Industrial Transfer - An Analysis Based on Data from 2002 to 2015. Economist. 2017, 4, 67-73.

Millimet, D.L.; Roy, J. Empirical tests of the Pollution Haven Hypothesis when environmental regulation is endogenous. J. Appl. Econom. 2016, 31, 623-645.

Mulatu. A.; Gerlagh, R.; Rigby, D.; et al. Environmental Regulation and Industry Location in Europe. Environ. Resour. Econ. 2010, 45, 459-479.

Ran, Q.; Xu, L. Environmental Regulation, Inter-provincial Industrial Transfer and Pollution 
Spillover Effect-Based on Spatial Durbin Model and Dynamic Threshold Panel Model. East. China. Econ. Manage. 2019, 33, 5-13.

Sarkodie, S.A.; Strezov, V. Effect of foreign direct investments, economic development and energy consumption on greenhouse gas emissions in developing countries. Sci. Total Environ. 2019, 646, 862-871.

Shen. J.; Wang, S.; Wei, L.; et al. Does migration of pollution-intensive industries impact environmental efficiency? Evidence supporting "Pollution Haven Hypothesis. J. Environ. Manage. 2019, 242, 142-152.

Tang, John. P. Pollution havens and the trade in toxic chemicals: Evidence from U.S. trade flows. Ecol. Econ. 2015, 112, 150-160.

Tian, H.; Wang, J. Research on Quality of Transport Infrastructure Along “The Belt and Road Initiatives"and China's Machinery Manufacturing Export--Empirical Analysis Based on the Random Effects Model. J. Ind. Technol. Econ. 2020, 2, 63-72.

Walter, I.; Ugelow, J. L. Environmental Policies in Developing Countries. Ambio, 1979, 8, 102-109.

Wang, L.; Xia, W. Study on Interregional Transfer Path of Pollution Industry in China. Econ. Geogr. 2019, 3, 152-161.

Wang, X.; Zhang, C.; Zhang, Z. Pollution haven or porter? The impact of environmental regulation on location choices of pollution-intensive firms in China. J. Environ. Manage. 2019, 248, 1-14.

World Wildlife fund. Living Planet Report 2016[EB/OL]. http://awsassets.panda.org/ downloads/lpr_living_planet_report_2016.pdf.

$\mathrm{Wu}, \mathrm{R}$. Research on the Influence of Labor Price Change on Industry Transfer in China. Price theory \& Practice 2017, 9, 36-39.

Xie, L.; Zhang, F.; Peng, Y. The Micro-mechanism for industrial transferring: A spatial economic model including double factors of market and policy. J. Hum.Univ.(Soc. Sci.).2016,30, 71-78.

Xing, Y.; Kolstad, D. Do Lax Environmental Regulations Attract Foreign Investment? Environ. Resour. Econ. 2002, 1, 1-22.

Xu, Z.; Wan,Q. A Research into the Influence of Relative Labor Cost on Gradient Transfer of Industry-Based on the Regional Differences in Labor Productivity. Econ. Surv. 2015, 5, 48-54. Xue, Y.; Zhang, J.; Yun, L. spatial agglomeration of Resource industry, transmission factor extraction and mediator effect of resource curse. Chinese. J. Manage. Sci. 2019,6,179-190.

Yu, D.; Xing, W. Government Performance Evaluation, Endogenous Environmental Regulation and Pollution Industry Transfer. J. Shanxi. Univ. Financ. Econ. 2019, 41, 1-15.

Yuan, B.; Ren, S.; Chen, X. Can environmental regulation promote the coordinated development of economy and environment in China's manufacturing industry? - A panel data analysis of 28 sub-sectors. J. Clean Prod. 2017, 149, 11-24.

Zhang, C.; Zhou, B.; LV, M.; et al. Has West China Development directly or indirectly brought Pollution Haven? China. Population. Resour. Environ. 2017, 27, 95-101.

Zhang, Y.; Wang, M.; Chen, B.; et al. The evaluation of labor supply support ability of labor-intensive industry transfer undertaking area. Stat. Decis. 2013, 1, 111-114.

Zhao, D.; Tony, F. Transfer Mode of Manufacturing Industry and Pollution Control. Res. Financ. Econ. Issues. 2013, 8, 29-34.

Zhao, J.; Zhang, L. Analysis on manufacturing industry shift in Pan-Yangtze River Delta based on "core-periphery" theory. J. Univ. Chinese. Acad. Sci. 2015, 32, 317-324.

Zhao, X.; Sun, B. The influence of Chinese environmental regulation on corporation innovation and competitiveness. J. Clean Prod. 2016, 112, 1528-1536.

Zheng, H.; Shi, P; He, J. Dynamic analysis of ecological footprint and ecological carrying capacity in Gansu Province. J. Arid Land. Resour. Environ. 2013, 27, 13-18.

Zhou, Y.; He, C.; Liu, Y. An Empirical Study on the Geographical Distribution of 
Pollution-Intensive Industries in China. J. Nat. Resour. 2015, 30, 1183-1196. 
Figures

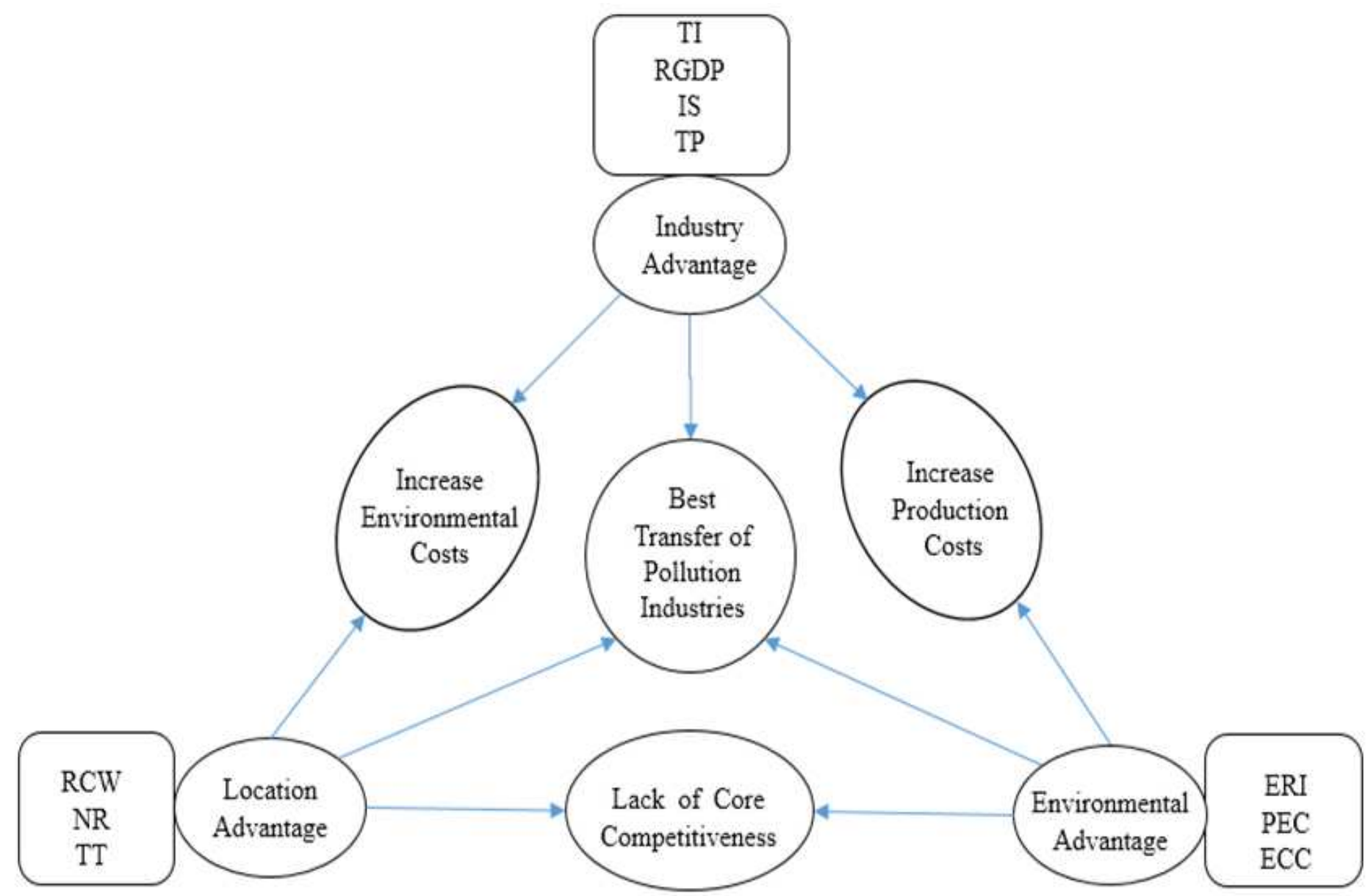

Figure 1

Triangular Relationship Model of Pollution Industry Transfer. 